\title{
Seed bank, seed size and dispersal in moisture gradients of temporary pools in Southern France
}

\author{
Kristin Metzner, Sophie Gachet, Pauline Rocarpin, Arne Saatkamp* \\ Aix Marseille Université, Institut Méditerranéen de Biodiversité et d'Ecologie, UMR 7263, CNRS, IRD, Université \\ d'Avignon, Faculté Saint Jérôme case 421, 13397 Marseille cedex 20, France
}

Received 23 January 2017; accepted 19 June 2017

Available online 27 June 2017

\begin{abstract}
Plants reduce risk of extinction due to unpredictable rainfall by soil seed banks, dispersal or large seeds. However, seed size also increases independently in dry habitats, and since seed size is in a trade-off with seed number, size of seed banks is expected to increase in moister habitats. Therefore, we wanted to test if seed abundance in soil increases in wet habitats, if seed size increases in dry habitats, and if spread of seeds along the gradient is higher for plants of intermediate habitats in local moisture gradients.

We studied 15 temporary pools in three biogeographically separated wetlands in Southern France. For each pool we studied five different moisture levels, totalling 75 local plant communities. We quantified soil seed bank by the seedling emergence method, seed size and an index of spatial spread of seeds in the soil for every species. We also quantified water levels for each plot.

We found increasing abundance of seeds in the soil with increasing water levels but lower seed size and higher spread at intermediate water levels. When we controlled for niche position, we found no trade-off between seed size, spread and abundance in the soil seed bank.

Type and importance of risk reduction strategies thus appeared to be strongly driven by the plant species' moisture niche and the spatial arrangement of water levels.
\end{abstract}

Keywords: Bet hedging; Vernal pool; Mediterranean; Risk reduction; Hydrological niche

\section{Introduction}

Climate change decreases rainfall predictablility and hence changes distribution of plants (Hooftman, Edwards, \& Bullock 2016). Drought and frost contribute to local extinctions (Harrison 2000; Inouye 2000). Plants reduce these risks, by evolving soil seed banks and seed dispersal. Both mul-

\footnotetext{
${ }^{*}$ Corresponding author.

E-mail address: arne.saatkamp@imbe.fr (A. Saatkamp).
}

tiply the opportunities for germination and thus ensure the long-term persistence of plant populations (Childs, Metcalf, \& Rees 2010; Cohen 1966; Philippi \& Seger 1989). Theoretical models and field data sustain the role of seed banks and dispersal for persistence in homogenous habitats (Bulmer 1984; Cohen 1966; Rees 1994; Tielbörger \& Valleriani 2005; Venable \& Brown 1988). These model assumptions contrast with the reality in many terrestrial ecosystems, which show small-scale gradients of soil moisture and hydrological niches, a gradient that has been shown to be a main fac- 
tor for co-existence in plant communities (Silvertown 2004; Silvertown, Araya, \& Gowing 2015). A trade-off between water use efficiency and relative growth rate seems to drive niche partitioning along the hydrological gradient (Angert, Huxman, Chesson, \& Venable 2009; Silvertown et al. 2015). Niche partitioning and risk-reduction are both important mechanisms for persistence, but we still do not know how niche partitioning relates to risk-reduction (Simons 2011). This is important because most plants grow separately in local gradients (e.g. García-Baquero, Silvertown, Gowing, \& Valle 2015) and perceive varying risk levels according to their niche boundaries.

Soil seed banks reduce risks when rainfall is unpredictable (Cohen 1966) and this strategy can result in high abundance of seeds in the soil (Volis \& Bohrer 2013). For deserts, one single global variance in rainfall is sufficient to model evolution of soil seed banks (Clauss \& Venable 2000; Venable 2007). However, in small-scale gradients of moisture, the response of plants to rainfall variability is less synchronous (García-Baquero et al. 2015; Tielbörger \& Petru 2008). In this case of uncorrelated local variances, when adjacent patches are different, seed dispersal is the optimal risk-reduction trait (Nathan \& Muller-Landau 2000; Siewert \& Tielbörger 2010; Snyder 2006; Venable \& Brown 1988). This suggests a shift of seed dispersal distances and seed bank abundances in moisture gradients, which has never been detected yet. Large seeds increase survival of seedlings under drought (Baker 1972; Daws, Crabtree, Dalling, Mullins, \& Burslem 2008; Leishman \& Westoby 1994) and hence decrease the risk of extinction of a plant species. Soil seed banks may thus be negatively correlated with seed size and positively correlated with moisture. Since seed size is in a well-known trade-off with seed number (Moles \& Westoby 2006), large seeds have lower abundance in the soil and limited dispersal (Bruun \& Poschlod 2006; Saatkamp, Affre, Dutoit, \& Poschlod 2009). Moreover, large seeds have been suggested a risk-reduction trait because they store resources to survive adverse times (Cohen 1966; Leishman \& Westoby 1994; Philippi \& Seger 1989; Siewert \& Tielbörger 2010). Models revealed a negative correlation between seed size, seed banks and seed dispersal for locally homogenous habitats (Cohen \& Levin 1987; Venable \& Brown 1988). Altogether, large seed size should be associated with dry habitats and trade-off with soil seed bank abundance and seed dispersal in the moister habitats.

Beyond seed size, plants differ in adaptations to hydrology leading to varying water use efficiency, e.g. by C3, C4 and CAM phytosynthesis (Keeley 1998) and in this way enable temporarily coexisting guilds (Angert et al. 2009) or coexistance in spatially partitioned hydrological niches (Ellenberg 1953; García-Baquero et al. 2015; Silvertown et al. 2015). It has been shown that niche partitioning in local moisture gradients contributes importantly to plant diversity (Bauder 2000; Violle et al. 2010). We therefore expect that effects of moisture niches on risk-reduction traits are strongest for moisture gradients on short spatial scales and when moisture gradients interfere with the extent of seed dispersal such as in Mediterranean temporary pools (Deil 2005). Temporary pools are also subjected to strong year-to-year fluctuations in rainfall, increasing the importance of risk-reduction and they are notoriously rich in annual plants (Deil 2005). Interestingly, year-to-year changes in surface are unequal for wet and dry habitats in the hydrological gradient. In wet years, high and steep areas remain dry while many lower parts are flooded, whereas in dry years even the lowest points remain dry. This implies that the importance of global versus local temporal variance experienced by plants differs according to their moisture niche in our gradient, i.e. aquatic plants have no escape and build up highly abundant soil seed banks (Bauder 2005), whereas plants with intermediate moisture niches should show higher seed dispersal.

Building on this context, we tested the following hypotheses on risk-reduction traits and moisture niches. (1) Abundance of seeds in soil banks increases towards the wet end of the moisture gradient, which is particularly pronounced in aquatic plants. (2) Dispersal of seeds in local gradients is highest for species with intermediate moisture niches, resulting in a higher spread in the soil seed bank for intermediate species. (3) Seed size increases for species from dry habitats, reducing the effects of drought. (4) Seed dispersal, seed bank abundance and seed size may be negatively related, since they are alternative strategies of risk reduction.

We quantified abundance and dispersal of seeds in the soil bank as well as seed size for all vascular plant species in 15 Mediterranean temporary pools. We also quantified changes of water level over short distances, which are known to vary inter-annually with rainfall and to drive small-scale turnover in these plant communities (Brock 2011; Deil 2005; Rhazi, Grillas, Tan Ham, \& El Khyari 2001).

\section{Materials and methods}

\section{Study sites}

We studied three temporary wetland areas in Southern France, Feuillane $\left(43^{\circ} 28^{\prime} 14^{\prime \prime} \mathrm{N}, 4^{\circ} 52^{\prime} 41^{\prime \prime} \mathrm{E}\right)$, Evenos $\left(43^{\circ} 12^{\prime} 40^{\prime \prime} \mathrm{N}, \quad 5^{\circ} 51^{\prime} 10^{\prime \prime} \mathrm{E}\right)$ and Plaine des Maures $\left(43^{\circ} 21^{\prime} 12^{\prime \prime} \mathrm{N}, 6^{\circ} 26^{\prime} 06^{\prime \prime} \mathrm{E}\right)$. At Feuillane, the mean annual temperature is $15.2 \pm 0.68^{\circ} \mathrm{C}$ and the mean annual rainfall is $455 \pm 158 \mathrm{~mm}$ (2004-2013, Istres). This site has alluvial soils with temporary pools in winter.

Evenos has a mean annual temperature of $16.4 \pm 0.47^{\circ} \mathrm{C}$ and a mean annual rainfall of $585 \pm 168 \mathrm{~mm}$ (2004-2013, Toulon). A layer of tertiary basalt is the substrate for temporary pools.

Plaine des Maures has a mean annual temperature of $15.4 \pm 0.56{ }^{\circ} \mathrm{C}$ and a mean annual rainfall of $747 \pm 299 \mathrm{~mm}$ (2004-2013, Le Luc). Permian sandstones form shallow soils and temporary streamlets and pools. This site is of prime interest for the conservation of temporary pools in Europe 
and harbors 27 rare or endagered plant (Grillas, Gauthier, Yavercovski, \& Perennou 2004).

\section{Sampling of established vegetation}

In each of the three study sites we selected five temporary pools and at each pool a transect was laid out from the deepest point at the pool bottom to a dry point in the surrounding area. Along each transect, we established five sampling plots (1-5 m apart). Each plot consisted of 20 small quadrates $(10 \times 10 \mathrm{~cm})$, which were arranged at right angles with the transect. Presence/absence of all vascular plants was recorded in each of the small quadrates, resulting in a total census area of $0.2 \mathrm{~m}^{2}$ per plot. For analysis, we only used a plant's frequency in the small quadrates at plot level. We gathered data from April to June 2012 for Feuillane and Evenos and in June 2013 for Plaine des Maures. Nomenclature of plant names follows Tison, Jauzein, and Michaud (2014).

\section{Soil seed bank sampling}

Around each plot we took 13 randomly placed soil cores. Cores had a diameter of $6 \mathrm{~cm}$ and a depth of $10 \mathrm{~cm}$. Before sampling, we removed vegetation and litter. We mixed soil samples for each plot. The mixed soil samples were transported and stored at $3-5^{\circ} \mathrm{C}$ until the emergence experiment. We sampled soil in April and June 2012 for Feuillane and Evenos and in June 2013 for Plaine des Maures. Sampling in spring avoided recently dispersed seeds and, hence, represents the persistent soil seed bank (Walck, Baskin, Baskin, \& Hidayati 2005). However, some seeds of Cardamine hirsuta, Polypogon maritimus and Erophila verna dispersed before sampling.

We quantified seeds in the soil using the seedling emergence method (ter Heerdt 1996). We concentrated soil samples using sieves of $4 \mathrm{~mm}$ and $0.1 \mathrm{~mm}$. The fine sieve retained even the smallest expected seeds (Juncus). These reduced samples were spread as a $0.5-\mathrm{cm}$ layer in trays filled with vermiculite and cultivated in an unheated greenhouse at Aix Marseille University. We inclined the trays in water-filled panels with one side water-saturated and the other side $5 \mathrm{~cm}$ above the water line. We pooled all data, since we did not detect strong differences in emergence between both sides, and since both aquatic and xerophytic plants germinated well in this setting. We cultivated soil samples from Feuillane and Evenos from July to September 2012 and for Plaine des Maures, from November 2013 to June 2014. We counted emerged seedlings every week and removed identified plants. Unidentified seedlings were cultivated until identification.

\section{Seed size}

2 We measured seed size as dry weight of three replicates of 10 or 50 seeds of five individuals per species in 2012 and 2013.

\section{Measurement and simulation of water levels in temporary pools}

We measured water levels (L) at five dates in spring 2013 and spring 2014 for each of the 15 studied temporary pools. We then compiled data on daily precipitation $(\mathrm{P})$ and daily potential evapo-transpiration (E) for the period 2011-2014 for each site. We used the simple water budget from Brooks (2004) to simulate water levels (in $\mathrm{cm}$ ) for each pool on a daily basis. This model uses three parameters (a, b and c), which we fitted by maximizing the $\mathrm{R}^{2}$ of the relation $\mathrm{L}[\mathrm{t}+1]=(\mathrm{L}[\mathrm{t}]+\mathrm{a} \times \mathrm{P}[\mathrm{t}+1]-\mathrm{b} \times \mathrm{E}[\mathrm{t}+1]) \times \mathrm{c}$ in a repeated linear regression. We then used the maximum water level obtained for each pool. We measured relative topographical heights of the different plots of all temporary pools with a water balance. The model for water level was run for the deepest point of each pool and we then substracted the topographical height to reach the water level value for each plot. This yielded negative water levels for dry habitats. We used these water levels as a surrogate for the moisture gradient in temporary pools and we calculated the mean and the median water level for each species.

\section{Statistical analyses}

We also used the position on an axis of Canonical Correspondence Analysis (CCA) as an alternative measure of a species' moisture niche (Ter Braak 1986). We performed a CCA on a plot by species matrix, and transect position and site as environment data using the default settings of the cca module in vegan/R (Oksanen et al. 2007). This forced the first axis parallel to the moisture gradient. We then compared a species' mean or median position on this axis from the established vegetation with its occurrence in the soil seed bank.

For comparisons between seed bank and standing vegetation we used box-plots of water levels or first CCA axis positions (Fig. 2) and t- or U-tests for comparison of means and Bartlett's test for variances.

In order to test the effect of moisture niche and seed size on the abundance of seeds in the soil, we used a zero-inflated negative binomial model to account for over-dispersion in our data (Zuur, Ieno, Walker, Saveliev, \& Smith 2009). We did a model selection based on likelihood-ratio tests and AICvalues as described in Zuur et al., 2009. The optimal model for the count part was the full model with seed size, gradient position and their interaction. For the presence-absence part, only seed size was retained as predictor.

We measured spread of seeds in the soil along the gradient in terms of water levels or CCA-axis using the interquartile range (IQR) of gradient positions of all seeds of a species, IQR has been proven to be independent of sample size and can be used to compare species in our setting since number of occurrences vary; since IQR can be sensible to outliers 

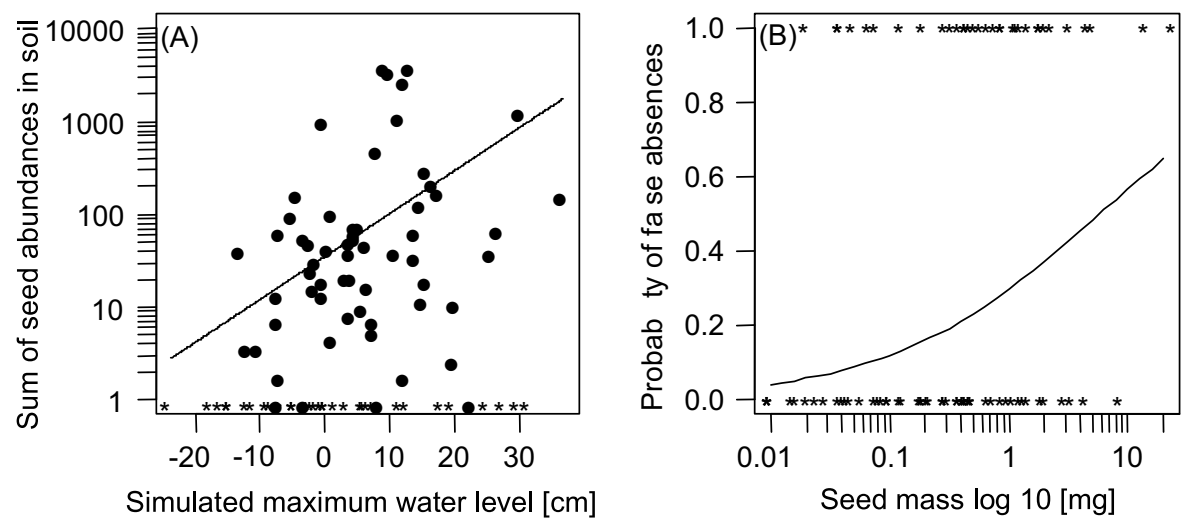

Fig 1. Abundance of a species seeds in the soil on its mean simulated water level. (A) Observed (dots, stars for zeros) and fitted counts according to a zero-inflated negative binomial model using seed size as covariate (abundance, straight line, $p=0.0060, z=2.74 ;$ seed size $\mathrm{p}<0.0001, \mathrm{z}=-4.124$ ). (B) Probability of false zero according to zero-inflated model (seed size, $\mathrm{p}=0.0487$, $\mathrm{z}=1.972$ ). See text for details.

we also calculated Rousseeuw and Croux's (1993) robust measure of scale as an alternative.

We tested the relation between moisture niche and spread by using a linear model of IQR on median seed positions in the gradient. Additionally, we wanted to know whether a non-linear model was more appropriate. We therefore also used generalized additive models (GAM) with two degrees of freedom to compare with the linear model. We also repeated all analyses using CCA axis in place of simulated water levels.

To study the relationship between seed size and moisture niche, we fitted a linear regression of log-transformed seed size against the median and mean of water levels for each species and of positions on the first CCA axis and alternatively compared it to a generalized additive model (GAM).

All analyses were performed in R (R-Core-Team 2014) using the packages vegan for CCA; $p s c l$ and lmtest for zeroinflated models and $m c g v$ for GAM.

\section{Results}

The abundance of seeds in the soil seed bank was positively related to increasing moisture in the habitats of a plant (linear model of log-transformed abundances only, $\mathrm{t}=2.2$, $p=0.0285$ ). This relation was even clearer when absences were included in a zero-inflated model with seed size as a covariate (Fig. 1). This indicates that species occurring in moist areas have higher abundances of seeds in the soil, independently of seed size (Fig. 1A). In this model, there was a weak interaction between seed size and gradient position, indicating that the effect of moisture niche was stronger for large than for small seeds. The correlation between plant position along the gradient and abundance in soil seed bank remained significant when median $(\mathrm{z}=2.6, \mathrm{p}=0.0092)$ instead of mean positions were used or when its maximum abundance $(z=2.040, p=0.0413)$ instead of total counts was used.

Moreover, the probability of an adult plant to be detected in the soil seed bank decreases with increasing seed size as illus- trated by the increase of false absences in the zero-inflated model (Fig. 1B). This relation between absence from seed bank and seed size was also found in a logistic regression on presence-absence data only $(\mathrm{z}=3.174, \mathrm{p}=0.0015)$.

For 46 species, we had at least three occurrences in both data sets, so we compared their positions along the moisture gradient between standing vegetation and soil seed bank visually using box plots (Fig. 2). This revealed that most species were restricted to a particular range of water levels as adult plants. When sorted by the median position of adult plants (Fig. 2), the soil seed bank of a plant tended to be on drier parts at the moist gradient end and on moister parts at the dry gradient end compared to adults.

Using data on mean niche position and spread (interquartile range) in the soil seed bank of 78 species, we found a non-linear relationship (GAM analysis with seed size and abundance in the soil seed bank as (non-significant) covariates), with spread being larger at intermediate gradient positions ( $\mathrm{n}=78, \mathrm{~F}=3.374, \mathrm{p}=0.0398$, Fig. 3 ). This was confirmed when we used the Rosseuw-Croux index instead of the inter-quartile range (GAM, $\mathrm{n}=78, \mathrm{~F}=4.024, \mathrm{p}=0.0221$ ) or when we used median positions instead of mean positions (GAM, $\mathrm{n}=78, \mathrm{~F}=3.509, \mathrm{p}=0.0352$ ) and neither abundances of seeds in the soil $(\mathrm{F}=0.661, \mathrm{p}=0.5195)$ nor seed size $(\mathrm{F}=0.022, \mathrm{p}=0.9782)$ had an effect on spread. A linear model on the same data did not show any trend $(\mathrm{df}=74$, $\mathrm{t}=-0.465, \mathrm{p}=0.644)$.

We also analyzed niche spread for each species in the standing vegetation with at least three occurrences, measured by the inter-quartile range in water levels (Fig. 3). We found that it did not change with mean position in a linear model $(\mathrm{df}=96, \mathrm{t}=0.1, \mathrm{p}=0.92)$, nor in a GAM $(\mathrm{n}=98, \mathrm{~F}=0.01$, $\mathrm{p}=0.92)$.

When we compared inter-quartile ranges between standing vegetation and soil seed bank, we found no overall significant difference ( $\mathrm{t}$-test, $\mathrm{t}=1.6, \mathrm{p}=0.1022, \mathrm{~N}=80$ ). This result did not change when a robust measure of spread (Rosseuw-Croux index) was used or when only species occurring in both data sets were used in a paired t-test 
Ranunculus ophioglossifolius

Lythrum hyssopifolia

Plantago coronopus

Laurentia michelii

Centaurium erythraea

Ranunculus peltatus

Ranunculus sardous

Juncus articulatus

Callitriche brutia

Anagallis minima

Poa annua

Polypogon maritimus Juncus pygmaeus

Ranunculus paludosus

Euphorbia maculata

Bromus hordaceus

Filago gallica

Lythrum thymifolium

Lythrum borysthenicum

Mentha pulegium

Sagina subulata

Ranunculus revelieri Juncus bufonius

Juncus tenageia

Polygonum aviculare

Vulpia bromoides

Teucrium scordium

Agrostis tenerrima

Gaudinia fragilis

Sisymbrella aspera

Dittrichia viscosa

Juncus capitatus

Cicendia filiformis

Trifolium campestre

Isolepis setacea

Crepis sancta

Moenchia erecta

Galium parisiense

Anagallis arvensis

Chaetonychia cymosa

Aira cupaniana

Bellis annua

Radiola linoides

Airopsis tenella

Tuberaria lignosa

Hypericum perforatum
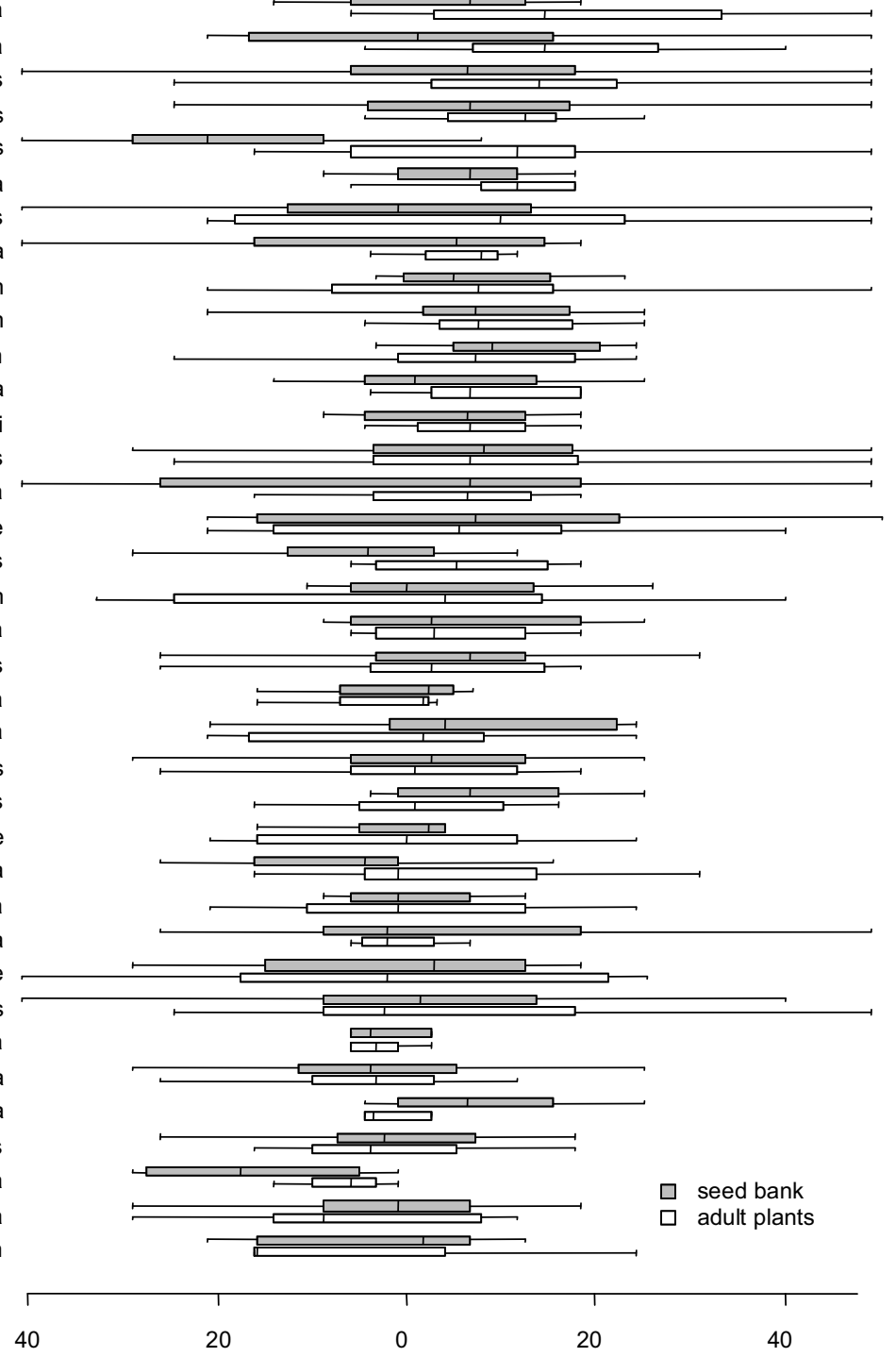

Simulated maximum water level $[\mathrm{cm}]$

Fig. 2. Distributions of seeds in the seed bank (grey) and adult plants (white) growing along transects ranging from the bottom of temporary pools to permanently dry places in the vicinity. Species are sorted by growing conditions of adult plants, with wet conditions at the top. Negative values of simulated maximum water levels indicate dry conditions.

$(\mathrm{t}=-0.4, \mathrm{df}=40, \mathrm{p}$-value $=0.6727)$. The non-linear effect of a higher spread at intermediate gradient positions was even stronger when the moisture related CCA-axis 1 was used instead of water levels (analysis not shown).

When we compared water levels for seeds from the soil compared to adult plants within species, only two species, Ranunculus paludosus $(\mathrm{t}=-2.3, \mathrm{df}=8, \mathrm{p}=0.0572)$ and
Lythrum hyssopifolia $(\mathrm{t}=-2.0, \mathrm{df}=15, \mathrm{p}=0.0524)$ tended to have adults in significantly moister conditions than seeds in the soil seed bank.

Additionally, comparing presence in the soil seed bank to the standing vegetation in the distribution along the gradient for each species separately, a Bartlett test of homogeneity of variances revealed that Lythrum borysthenicum $\left(\mathrm{K}^{2}=4.441\right.$, 


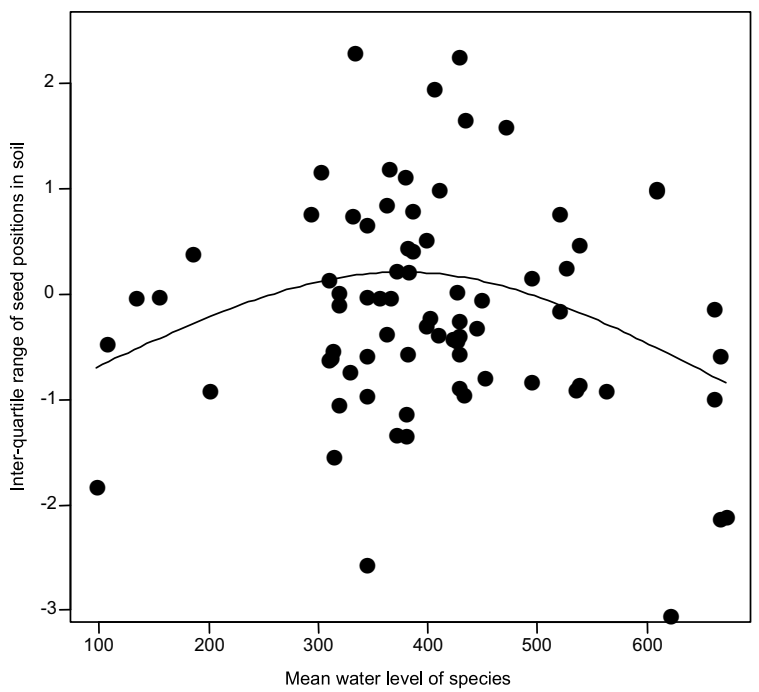

Fig. 3. Seed spread in soil along the gradient (inter-quartile range) on mean water level of a species and fitted line from a generalized additive model $(\mathrm{n}=78, \mathrm{~F}=3.374, \mathrm{p}=0.0398)$ with seed size and seed abundance as covariates. Inter-quartile range is square-root transformed and water level transformed to $(x+50)^{1.5}$ to lessen leftskew.

$\mathrm{p}=0.0351)$, Juncus tenageia $\left(\mathrm{K}^{2}=8.5911, \mathrm{p}=0.0034\right)$ and Moenchia erecta $\left(\mathrm{K}^{2}=4.5512, \mathrm{p}=0.0329\right)$ had significantly greater variance in the soil seed bank and only Mentha pulegium $\left(\mathrm{K}^{2}=3.8831, \mathrm{p}=0.0488\right)$ had greater spread in the standing vegetation.

Using CCA axis coordinates instead of water levels to study positions of seeds from the soil compared to adults revealed that $R$. paludosus seeds $(\mathrm{t}=-4.3, \mathrm{df}=8, \mathrm{p}=0.0023)$ were found in drier conditions than the adult plants in the vegetation. A similar difference was found for Tuberaria guttata $(\mathrm{t}=2.4, \mathrm{df}=12, \mathrm{p}=0.0354)$.

Using the CCA-axis, nine species (Callitriche brutia, Isolepis setacea, Juncus articulatus, Juncus bufonius, Juncus tenageia, Lythrum borysthenicum, Poa annua, Polypogon maritimus, Ranunculus peltatus, Sagina subulata) showed a larger spread in the soil seed bank compared to the standing vegetation (Bartlett's test of homogeneity of variances, $\left.\mathrm{K}^{2}=4.2-23.4, \mathrm{p}<0.05\right)$. Only Juncus pygmaeus $\left(\mathrm{K}^{2}=4.2\right.$, $\mathrm{p}=0.0348)$ and Plantago coronopus $\left(\mathrm{K}^{2}=3.1, \mathrm{p}=0.0796\right)$ had higher spread in the standing vegetation.

Seed size of a species decreased significantly (Fig. 4) with increasingly moist niches of adults as measured by their median position in the gradient. Analyzing the data set with non-linear regression methods $\left(\mathrm{GAM} \mathrm{R} \mathrm{R}^{2}=0.14, \mathrm{~F}=8.699\right.$, $\mathrm{p}=0.0003$ ) only slightly increased $\mathrm{R}^{2}$ compared to the linear model and revealed again a generally decreasing seed size with increasing moisture. The species position on the moisture-related CCA-axis was also linearily related to seed size $\left(\mathrm{p}<0.0001, \mathrm{t}=4.3, \mathrm{R}^{2}=0.17\right)$. Analyzing this data as community-weighted means of seed size yielded a much weaker relationship ( $\mathrm{p}=0.049$, marginal $\mathrm{R}^{2}=0.02$ ).

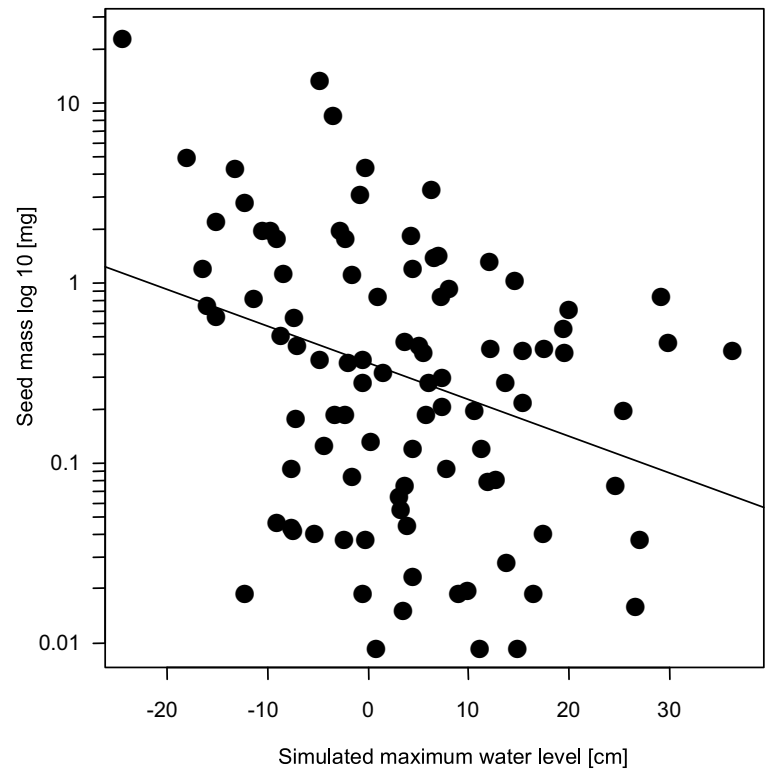

Fig. 4. Seed size (weight on log-scale) and mean simulated water levels for 95 species of temporary pools. The regression line was calculated from a linear model on log-transformed data $(\mathrm{p}=0.00172$, $\mathrm{t}=-3.2, \mathrm{R} 2=0.10$ ). Only species with at least 3 records are included. See Materials and methods section for details of water level simulation.

There was a significant negative relation between logtransformed seed size and log-transformed abundance in the soil seed bank with a slope of $-0.3 \pm 0.1 \quad(t=-2.480$, $\mathrm{p}=0.0154)$. With gradient position as a covariate, there was no relation between seed size or seed abundance and measures of seed spread in the soil.

\section{Discussion}

Seed bank abundance and probability of detection of plant species in the seed bank by the seedling emergence method increased continuously with increasingly moist habitats, extending previous studies that reported generally high levels of seed bank for ephemeral wetlands (Brock 2011; Cross et al. 2015; Faist \& Collinge 2015; Leck \& Brock 2000; Rhazi et al. 2001). The effect of moisture niche on seed bank is statistically independent from seed size in our data and is thus not triggered by increasing seed size due to drought adaptation (Leishman \& Westoby 1994). The high level of risk of aquatic species suggested by their abundant soil seed banks underlines previous studies showing that these species rely heavily on soil seed banks (Bonis, Lepart, \& Grillas 1995; Brock 2011). Increasing soil seed banks with higher moisture might be interpreted as a consequence of gravitational movement of seeds in vernal pools. However, moisture is the main factor that changes consistently in our transects even in flat or very rugged areas. Moreover, abundance of soil seed bank has been analyzed for position of adult plants, not for seed positions, and species show spe- 
cific lower limits of seed distributions (Figs. $1 \mathrm{~A}$ and 2). We therefore think that moisture niches of adult plants trigger this change in the soil seed bank more than gravitational movement. Higher seed densities for the bottom compared to the margins of Californian vernal pools confirm this tendency for other regions (Faist \& Collinge 2015) and point to a relation between moisture niche and seed banking. Plants can achieve high abundance of seeds in the soil by producing high numbers of small seeds, increased levels of dormancy, light and fluctuating temperature requirements (Saatkamp et al. 2009; Saatkamp, Poschlod, \& Venable 2014). For plants of Mediterranean temporary pools detailed laboratory studies (Carta 2016; Carta, Bedini, Müller, \& Probert 2013) indicate light and diurnally fluctuating temperature requirements as mechanisms for the build up of soil seed banks and that anoxia prevents germination. Experimental studies trying to exhaust seed banks of Australian temporary pools showed that many effective watering cycles or more than twelve years of successive exposure to germination seasons are needed to deplete soil seed banks to a low level, indicating that dormancy and specific germination conditions maintain an ungerminated but viable seed reservoir in the soil of temporary pools (Brock 2011; Cross et al. 2015). Together with data presented here this suggests that a gradient of increasing seed banking built upon adaptive traits such as germination requirements and reduced seed size exists from the surroundings to the interior of temporary pools.

Seeds recorded in the soil seed bank showed higher spread along the gradient for species with intermediate moisture requirements. This was independent of soil seed abundance or seed size, which confirms that spread measures were independent of sample size. We acknowledge that small-scale dispersal for individual plants can only be quantified by using seed traps around isolated individuals during the dispersal season (Bonis, Lepart, \& Grillas 1995), but we think that spread of seeds trapped by soil is an indicator of small-scale dispersal. Higher spread of the seeds in the soil seed bank for intermediate species can also result from year-to-year shifting of above ground plant populations. However, it is difficult to quantify how much this shifting contributes to seed spread in our data compared to different dispersal distances. Nevertheless, when populations move according to moving environmental conditions, all species should have similar spreads of seeds in the soil including aquatic or xerophytic species, but this is not the case in our data, where we detected a higher spread of intermediate species, while controlling for seed production. We suggest that a modelling approach and in situ dispersal data are needed to quantify dispersal in moisture gradients.

Evidently, species on the moist or dry gradient end cannot move to better patches on a local scale, since in extreme years there are no moister or drier sites and adult plants would die from drought or flooding. Plants must thus have other adaptations for local persistence without movement such as a seed bank or a large seed size. These might be combined with adaptations for long distance dispersal instead of local scale dispersal such as hooks (Fischer, Poschlod, \& Beinlich 1996; Römermann, Tackenberg, \& Poschlod 2005) or adaptations for long distance dispersal by wind (Cheptou, Carrue, Rouifed, \& Cantarel 2008). The effective long distance dispersal for aquatic species by water and birds is a long known fact (Darwin 1859; Figuerola 2002). But, short distance dispersal of these species is very difficult to assess.

Species shifted their mean gradient positions between soil seed bank and standing vegetation. The two species with a significant shift, $R$. paludosus and L. hyssopifolia, have high moisture requirements and occupied a moister niche as plants in the vegetation than as seeds in the soil seed bank. Evidence for a larger spread in the soil seed bank for individual species is stronger, three of four species for which there was a significant difference in spread above and below ground had larger spread in the soil seed bank and all of these had intermediate positions. These results suggest that maintaining a high spread of the seed bank in local gradients for annual plants is a mechanism to enhance local population persistence at intermediate gradient positions.

Plant species growing in dry parts showed consistently higher seed size than species from intermediate or moist plots. This finding supports the adaptive value of large seeds in dry environments (Baker 1972; Daws et al. 2008; Leishman \& Westoby 1994). Interestingly, plants with large seeds have smaller interannual variability in survival (Metz et al., 2010; Pake \& Venable 1996). Here we suggest that risk reduction traits are related to the niche position of a species in smallscale moisture gradients. Plants in dry parts, seem to rely more on conservative bet hedging via larger seed size. In our data, species with seeds lighter than $1 \mathrm{mg}$ only occurred on plots waterlogged during the observation year (Fig. 4). Probably, many large seeds without impermeable teguments would also die in prolonged periods of flooding, and thus contribute to the size-hydrology relation.

We found no evidence for a trade-off between dispersal and seed bank with the indices and at the scale we studied. Including seed size and gradient position, both potential confounding factors with significant effect on dispersal and seed bank abundance, did not change this picture. However, our data support the idea that abundance of seeds in the soil is linked to seed size via the seed size-number trade-off, including a higher detectability of light and more numerous seeds (Saatkamp et al. 2014; Thompson, Band, \& Hodgson 1993).

Rather than being in a trade-off, seed size and seed bank were both positively correlated to moisture. This suggests that seed banks or heavy seeds are not alternative bet hedging strategies at a given moisture condition (Pake \& Venable 1996; Venable and Brown 1988) but that the main differences in these traits are triggered by differences in a plant's moisture niche. Moreover, our findings do not sustain the idea of a trade-off between dispersal and seed bank that has been suggested by theoretical works (e.g. Venable \& Lawlor 1980). Since both dispersal (Bruun \& Poschlod 2006) and seed banks (Saatkamp et al. 2009) depend on high seed production, seed production increases the probability of a seed to reach dis- 
tant places or times. Dispersal and seed banks are therefore positively related instead of being in a trade-off. Moreover, a higher productivity is known for light-seeded plants due to the seed number-mass trade-off (Jakobsson \& Eriksson 2000; Moles, Falster, Leishman, \& Westoby 2004), so one way to increase seed number adaptively is via decreasing seed size (Shipley \& Dion 1992). Possibly, stronger spatial and temporal variability in moisture both select for increased seed number, lowering seed size at the moist gradient end.

Probably, our results on risk-reduction may also be found in other rainfall-related local moisture gradients since even outside the context of temporary pools, small-scale moisture gradients move from one year to another. The different niche positions and adaptations of plants to drought and water-logged soils are, therefore, just one explanation for differences in the temporal variance between species within communities (Angert et al. 2009; Venable 2007).

Our data sustain the view of Childs et al. (2010) that diversifying bet hedging should be favored in situations when escape in space or time is possible, which is the case for persistent soil seed banks of aquatic species in our data.

\section{Acknowledgments}

We are grateful to Dominique Guicheteau (Réserve Naturelle Plaine des Maures) and SOMECA for access to study site and DREAL PACA and CNPN for permits. We thank Patrick Grillas and Alexandre Millon for helpful discussions and Daniel Pavon and Manon Batista for fieldwork and Frauke Behrendt (University of Brighton) for English language revision. SG benefits from IKEA grant to IMBE 13/8/2009 and AS from Région Provence Alpes Côte d'Azur grant "Gévoclé".

\section{References}

Angert, A. L., Huxman, T. E., Chesson, P., \& Venable, D. L. (2009). Functional tradeoffs determine species coexistence via the storage effect. Proceedings of the National Academy of Sciences, 106, 11641-11645.

Baker, H. G. (1972). Seed weight in relation to environmental conditions in California. Ecology, 53, 997-1010.

Bauder, E. T. (2000). Inundation effects on small-scale plant distributions in San Diego, California vernal pools. Aquatic Ecology, 34, 43-61.

Bauder, E. T. (2005). The effects of an unpredictable precipitation regime on vernal pool hydrology. Freshwater Biology, 50, 2129-2135.

Bonis, A., Lepart, J., \& Grillas, P. (1995). Seed bank dynamics and coexistence of annual macrophytes in a temporary and variable habitat. Oikos, 74, 81-92.

Brock, M. A. (2011). Persistence of seed banks in Australian temporary wetlands. Freshwater Biology, 56, 1312-1327.

Brooks, D. R. (2004). Weather-related effects on woodland vernal pool hydrology and hydroperiod. Wetlands, 24, 104-114.
Bruun, H. H., \& Poschlod, P. (2006). Why are small seeds dispersed through animal guts: Large numbers or seed size per se? Oikos, 113, 402-411.

Bullock, J. M., Shea, K., \& Skarpaas, O. (2006). Measuring plant dispersal: An introduction to field methods and experimental design. Plant Ecology, 186, 217-234.

Bulmer, M. G. (1984). Delayed germination of seeds: Cohen's model revisited. Theoretical Population Biology, 26, 367-377.

Carta, A. (2016). Seed regeneration in Mediterranean temporary ponds: Germination ecophysiology and vegetation processes. Hydrobiologia, 782, 23-35.

Carta, A., Bedini, G., Müller, K. J., \& Probert, R. J. (2013). Comparative seed dormancy and germination of eight annual species of ephemeral wetland vegetation in a Mediterranean climate. Plant Ecology, 214, 339-349.

Cheptou, P. O., Carrue, O., Rouifed, S., \& Cantarel, A. (2008). Rapid evolution of seed dispersal in an urban environment in the weed Crepis sancta. Proceedings of the National Academy of Sciences, USA, 105, 3796-3796.

Childs, D. Z., Metcalf, C. J. E., \& Rees, M. (2010). Evolutionary bet-hedging in the real world: Empirical evidence and challenges revealed by plants. Proceedings of the Royal Society B: Biological Sciences, 2777, 3055-3064.

Clauss, M. J., \& Venable, D. L. (2000). Seed germination in desert annuals: An empirical test of adaptive bet hedging. American Naturalist, 155, 168-186.

Cohen, D. (1966). Optimizing reproduction in a randomly varying environment. Journal of Theoretical Biology, 12, 119-129.

Cohen, D., \& Levin, S. A. (1987). The interaction between dispersal and dormancy strategies in varying and heterogeneous environments. In Mathematical topics in population biology, morphogenesis and neurosciences. pp. 110-122. Springer.

Cross, A. T., Turner, S. R., Renton, M., Baskin, J. M., Dixon, K. W., \& Merritt, D. J. (2015). Seed dormancy and persistent sediment seed banks of ephemeral freshwater rock pools in the Australian monsoon tropics. Annals of Botany, 115, 847-859.

Darwin, C. (1859). On the origin of species by means of natural selection, or preservation of favored races in the struggle for life. London: Murray.

Daws, M. I., Crabtree, L. M., Dalling, J. W., Mullins, C. E., \& Burslem, D. F. R. P. (2008). Germination responses to water potential in neotropical pioneers suggest large-seeded species take more risks. Annals of Botany, 102, 945-951.

Deil, U. (2005). A review on habitats, plant traits and vegetation of ephemeral wetlands - A global perspective. Phytocoenologia, 35, 533-706.

Ellenberg, H. (1953). Physiologisches und ökologisches Verhalten derselben Pflanzenarten. Berichte der Deutschen Botanischen Gesellschaft, 65, 351-362.

Faist, A. M., \& Collinge, S. K. (2015). Seed bank composition varies along invasion and inundation gradients in vernal pool wetlands. Plant Ecology, 216, 553-564.

Figuerola, J. (2002). Dispersal of aquatic organisms by waterbirds: A review of past research and priorities for future studies. Freshwater Biology, 47, 483-494.

Fischer, S. F., Poschlod, P., \& Beinlich, B. (1996). Experimental studies on the dispersal of plants and animals on sheep in calcareous grasslands. Journal of Applied Ecology, 33, 1206-1222. 
García-Baquero, G., Silvertown, J., Gowing, D. J., \& Valle, C. J. (2015). Dissecting the hydrological niche: Soil moisture, space and lifespan. Journal of Vegetation Science, 27, 219-226.

Grillas, P., Gauthier, P., Yavercovski, N., \& Perennou, C. (2004). Mediterranean temporary pools; Vol. 1-Issues relating to conservation, functioning and management. Station biologique de la Tour du Valat.

Harrison, R. D. (2000). Repercussions of El Nino: Drought causes extinction and the breakdown of mutualism in Borneo. Proceedings of the Royal Society B, 267, 911-915.

Hooftman, D. A., Edwards, B., \& Bullock, J. M. (2016). Reductions in connectivity and habitat quality drive local extinctions in a plant diversity hotspot. Ecography, 39, 583-592.

Inouye, B. D. (2000). The ecological and evolutionary significance of frost in the context of climate change. Ecology Letters, 3, 457-463.

Jakobsson, A., \& Eriksson, O. (2000). A comparative study of seed number, seed size: seedling size and recruitment in grassland plants. Oikos, 88, 494-502.

Keeley, J. E. (1998). CAM photosynthesis in submerged aquatic plants. The Botanical Review, 64, 121-175.

Leck, M. A., \& Brock, M. A. (2000). Ecological and evolutionary trends in wetlands: Evidence from seeds and seed banks in New South Wales, Australia and New Jersey, USA. Plant Species Biology, 15, 97-112.

Leishman, M. R., \& Westoby, M. (1994). The role of seed size in seedling establishment in dry soil conditions - Experimental evidence from semi-arid species. Journal of Ecology, 82, 249-258.

Metz, J., Liancourt, P., Kigel, J., Harel, D., Sternberg, M., \& Tielbörger, K. (2010). Plant survival in relation to seed size along environmental gradients: A long-term study from semi-arid and Mediterranean annual plant communities. Journal of Ecology, 98, 697-704.

Moles, A. T., Falster, D. S., Leishman, M. R., \& Westoby, M. (2004). Small-seeded species produce more seeds per square metre of canopy per year, but not per individual per lifetime. Journal of Ecology, 92, 384-396.

Moles, A. T., \& Westoby, M. (2006). Seed size and plant strategy across the whole life cycle. Oikos, 113, 91-105.

Nathan, R., \& Muller-Landau, H. C. (2000). Spatial patterns of seed dispersal, their determinants and consequences for recruitment. Trends in Ecology \& Evolution, 15, 278-285.

Oksanen, J., Kindt, R., Legendre, P., O'Hara, B., Simpson, G. L., Solymos, P., et al. (2007). Vegan: Community ecology package. R package version 2. 2-0.

Pake, C. E., \& Venable, D. L. (1996). Seed banks in desert annuals: Implications for persistence and coexistence in variable environments. Ecology, 77, 1427-1436.

Philippi, T., \& Seger, J. (1989). Hedging one's evolutionary bets, revisited. Trends in Ecology \& Evolution, 4, 41-44.

R-Core-Team. (2014). $R$ : A language and environment for statistical computing. Vienna, Austria: R Foundation for Statistical Computing.

Rees, M. (1994). Delayed germination of seeds: A look at the effects of adult longevity, the timing of reproduction, and population age/stage structure. American Naturalist, 144, 43-64.

Rhazi, L., Grillas, P., Tan Ham, L., \& El Khyari, D. (2001). The seed bank and the between years dynamics of the vegetation of a Mediterranean temporary pool (NW Morocco). Ecologia Mediterranea, 27, 69-88.

Römermann, C., Tackenberg, O., \& Poschlod, P. (2005). How to predict attachment potential of seeds to sheep and cattle coat from simple morphological seed traits. Oikos, 110, 219-230.

Rousseeuw, P. J., \& Croux, C. (1993). Alternatives to the median absolute deviation. Journal of the American Statistical Association, 88, 1273-1283.

Saatkamp, A., Affre, L., Dutoit, T., \& Poschlod, P. (2009). The seed bank longevity index revisited: Limited reliability evident from a burial experiment and database analyses. Annals of Botany, 104, 715-724.

Saatkamp, A., Poschlod, P., \& Venable, D. L. (2014). The functional role of soil seed banks in natural communities. In R. S. Gallagher (Ed.), Seeds - The ecology of regeneration in plant communities (pp. 263-294). Wallingford: CABI.

Shipley, B., \& Dion, J. (1992). The Allometry of Seed Production in Herbaceous Angiosperms. American Naturalist, 139, 467-483.

Siewert, W., \& Tielbörger, K. (2010). Dispersal-dormancy relationships in annual plants: Putting model predictions to the test. American Naturalist, 176, 490-500.

Silvertown, J. (2004). Plant coexistence and the niche. Trends in Ecology \& Evolution, 19, 605-611.

Silvertown, J., Araya, Y., \& Gowing, D. (2015). Hydrological niches in terrestrial plant communities: A review. Journal of Ecology, 103, 93-108.

Simons, A. M. (2011). Modes of response to environmental change and the elusive empirical evidence for bet hedging. Proceedings of the Royal Society B-Biological Sciences, 278, 1601-1609.

Snyder, R. E. (2006). Multiple risk reduction mechanisms: Can dormancy substitute for dispersal? Ecology Letters, 9, 1106-1114.

Ter Braak, C. J. (1986). Canonical correspondence analysis: A new eigenvector technique for multivariate direct gradient analysis. Ecology, 67, 1167-1179.

ter Heerdt, G. N. J. (1996). An improved method for seed-bank analysis: Seedling emergence after removing the soil by sieving. Functional Ecology, 10, 144-151.

Thompson, K., Band, S. R., \& Hodgson, J. G. (1993). Seed size and shape predict persistence in soil. Functional Ecology, 7, 236-241.

Tielbörger, K., \& Petru, M. (2008). Germination behaviour of annual plants under changing climatic conditions: Separating local and regional environmental effects. Oecologia, 155, 717-728.

Tielbörger, K., \& Valleriani, A. (2005). Can seeds predict their future? Germination strategies of density-regulated desert annuals. Oikos, 111, 235-244.

Tison, J. M., Jauzein, P., \& Michaud, H. (2014). Flore de la France méditerranéenne continentale. Turriers: Naturalia Publications.

Venable, D. L. (2007). Bet hedging in a guild of desert annuals. Ecology, 88, 1086-1090.

Venable, D. L., \& Brown, J. S. (1988). The selective interaction of dispersal, dormancy and seed size as adaptations for reducing risks in variable environments. American Naturalist, 131, 360-384.

Venable, D. L., \& Lawlor, L. (1980). Delayed germination and dispersal in desert annuals: Escape in space and time. Oecologia, 46, 272-282. 
Violle, C., Bonis, A., Plantegenest, M., Cudennec, C., Damgaard, C., Marion, B., et al. (2010). Plant functional traits capture species richness variations along a flooding gradient. Oikos, 120, 389-398.

Volis, S., \& Bohrer, G. (2013). Joint evolution of seed traits along an aridity gradient: Seed size and dormancy are not two substitutable evolutionary traits in temporally heterogeneous environment. New Phytologist, 197, 655-667.
Walck, J. L., Baskin, J. M., Baskin, C. C., \& Hidayati, S. N. (2005). Defining transient and persistent seed banks in species with pronounced seasonal dormancy and germination patterns. Seed Science Research, 15, 189-196.

Zuur, A. F., Ieno, E. N., Walker, N. J., Saveliev, A. A., \& Smith, G. M. (2009). Mixed effects, models and extensions in ecology with $R$. New York: Springer. 